\title{
CORONARY FLOW RESERVE TO ASSESS MICROCIRCULATION WITH ECHOCARDIOGRAPHY: BASIC CONCEPTS, NEW INSIGHT AND FUTURE PRESPECTIVES.
}

Andreina Carbone ${ }^{1}$, Antonello D'Andrea ${ }^{2}$, Simona Sperlongano ${ }^{3}$, Ercole Tagliamonte ${ }^{4}$, Giulia Mandoli ${ }^{5}$, Ciro Santoro ${ }^{6}$, Vincenzo Evola ${ }^{7}$, Francesco Bandera ${ }^{8}$, Doralisa Morrone ${ }^{9}$, Alessandro Malagoli ${ }^{10}$, Flavio D'Ascenzi ${ }^{11}$, eduardo bossone ${ }^{12}$, and Matteo Cameli ${ }^{11}$

${ }^{1}$ Universita degli Studi della Campania Luigi Vanvitelli

${ }^{2}$ Second University of Naples

${ }^{3}$ University of Campania Luigi Vanvitelli School of Medicine and Surgery

"Umberto I" Hospital

${ }^{5}$ University of Siena Faculty of Medicine and Surgery

${ }^{6}$ University of Naples Federico II

${ }^{7}$ University of Palermo

${ }^{8}$ IRCCS Policlinico San Donato

${ }^{9}$ Cisanello Hospital

${ }^{10}$ Nuovo Ospedale Civile Sant'Agostino Estense di Baggiovara

${ }^{11}$ University of Siena

${ }^{12}$ Ospedale Cardarelli

November 16, 2020

\begin{abstract}
Coronary flow reserve is the capacity of the coronary circulation to augment the blood flow in response an increase in myocardial metabolic demands and has a powerful prognostic significance in different clinical situations. It might assess with invasive and non-invasive technique. Transthoracic echocardiography Doppler is an emerging diagnostic technique, noninvasive, highly feasible, safe for patient and physician, without radiation, able to detect macrovascular and microvascular anomalies in the coronary circulation. This review aims to describe the benefit and limits of noninvasive assessment of coronary flow reserve, in particular his evaluation with echocardiography.
\end{abstract}

\section{Hosted file}

CRF e microcirculation 14.11.2020 post plag.pdf available at https://authorea.com/ users/341380/articles/493173-coronary-flow-reserve-to-assess-microcirculation-withechocardiography-basic-concepts-new-insight-and-future-prespectives 

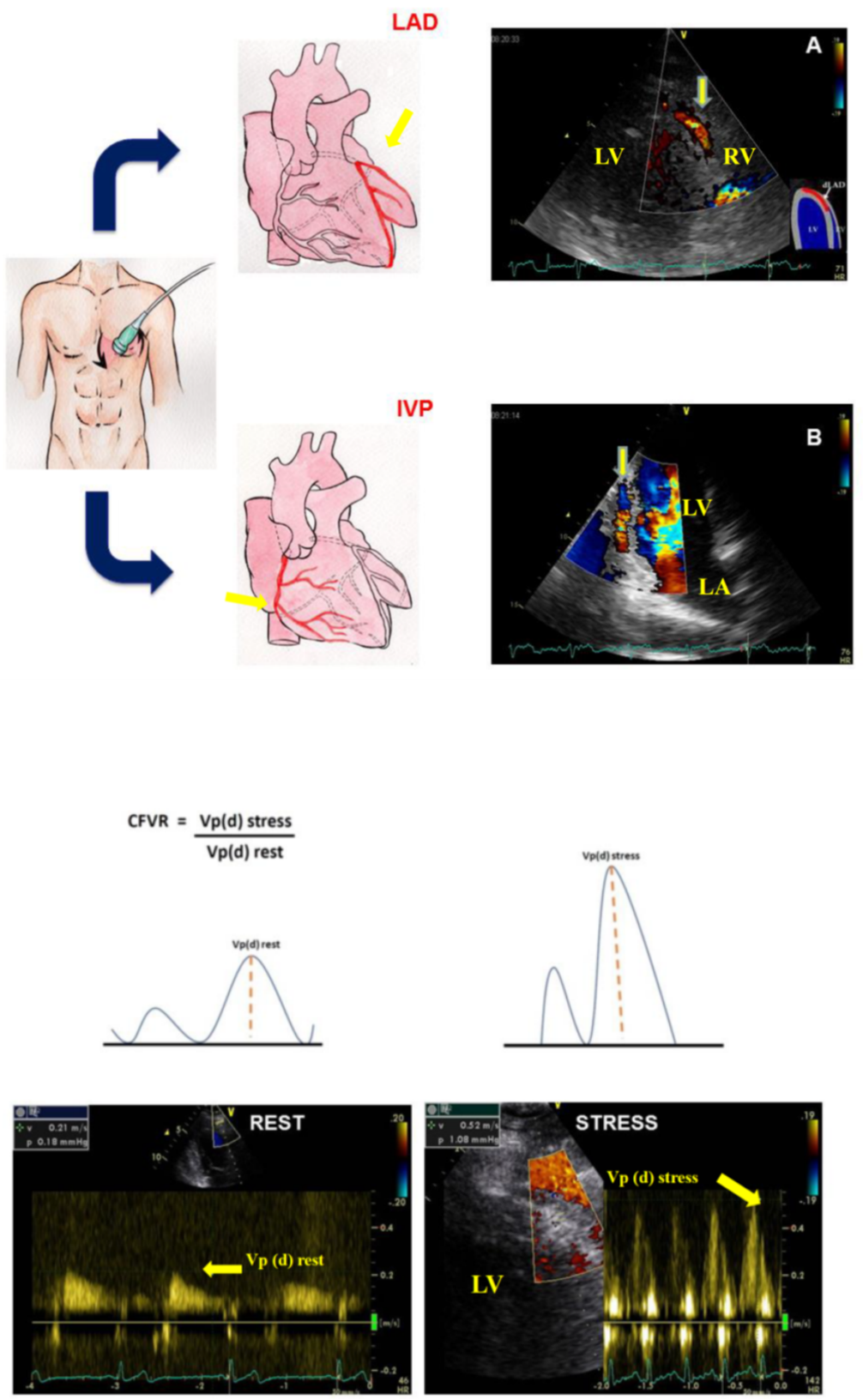

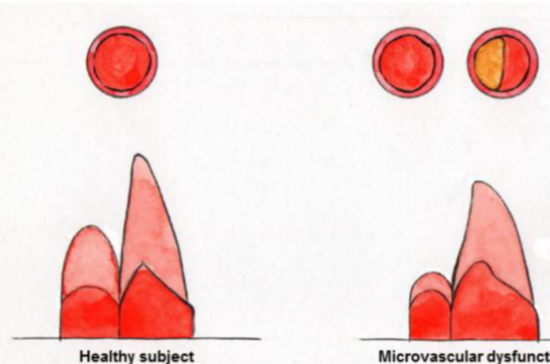

Healthy subject

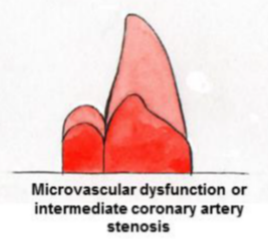

stenosis

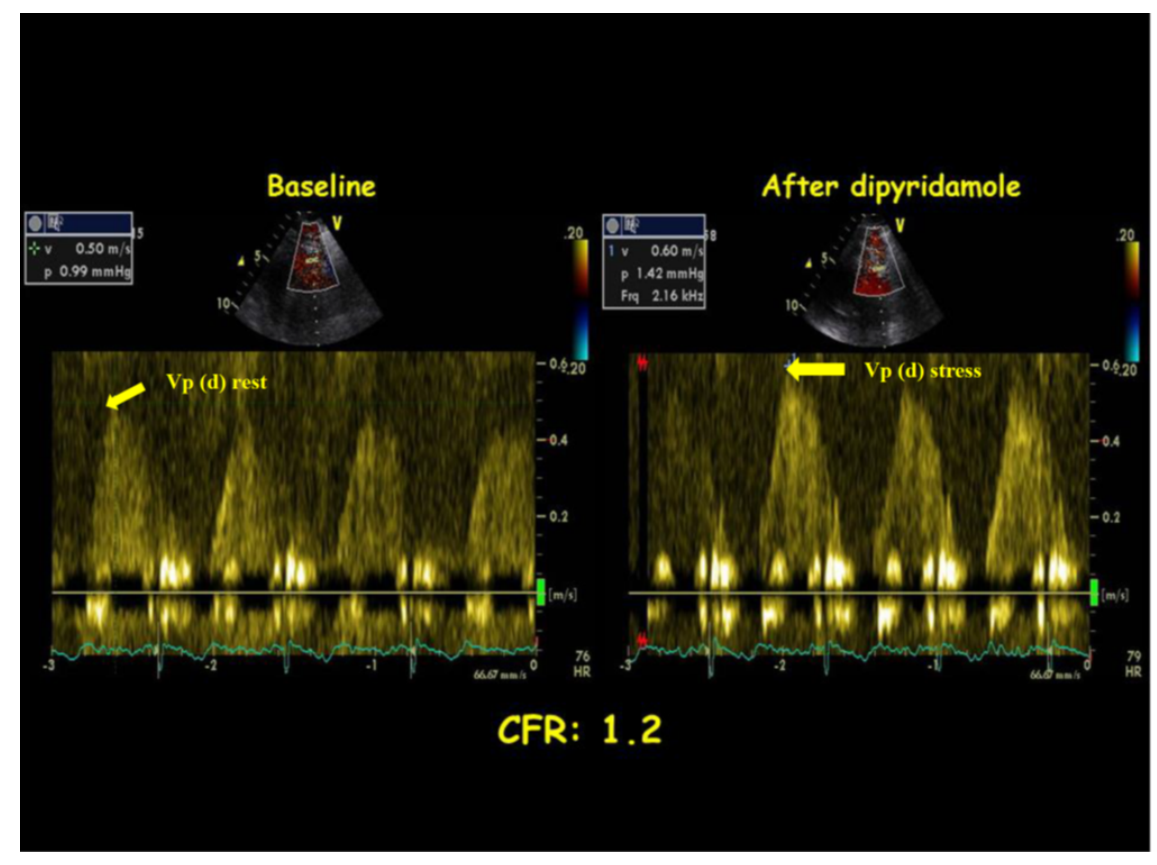

